\section{A publicação de erratas no jornalismo online: parâmetros éticos para uma discussão acerca de condutas mais adequadas}

Errata publication on online journalism: ethical parameters for a discussion regarding sensible conduct

Lívia de Souza Vieira

\section{Resumo}

O presente artigo tem como base o projeto de pesquisa aprovado no Programa de Pós-Graduação em Jornalismo da Universidade Federal de Santa Catarina (UFSC-2012). A partir da identificação das modalidades de comunicação do erro nos principais webjornais brasileiros e da análise de uma errata selecionada, o artigo pretende levantar reflexões para condutas mais adequadas e eficientes, contemplando princípios éticos do jornalismo, especialmente aqueles que convergem com o jornalismo online. Parte-se do princípio de que há uma deficiência nas modalidades atuais de publicação
Mestranda do Programa de PósGraduação em Jornalismo da Universidade Federal de Santa Catarina (UFSC), professora do curso de Jornalismo da Associação Educacional Luterana (Bom Jesus/IELUSC), Joinville, SCBrasil, e-mail: liviasvieira@uol.com.br
Palavras-chave: Errata.

Jornalismo online. Ética. Leitor. Qualidade jornalística. 
de erratas e uma necessidade de descobrir uma maneira pela qual o leitor seja informado com precisão sobre os fatos. Nesse contexto, compreende-se a errata como o instrumento que dá visibilidade ao erro jornalístico e deve ser utilizada todas as vezes em que a notícia necessitar de correção. Seu caráter é de prestação de contas com o público leitor, pois, agindo com transparência na admissão de erros, o veículo mantém sua credibilidade.

\section{Abstract}

The present article is based on the research project, approved for Journalism Post-Graduate Program of Federal University of Santa Catarina (UFSC - 2012). The article intends to raise the discussion about effective and adequate conducts, covering the journalistic ethical principles - focusing specially on the ones directed to online journalism - on the main Brazilian online newspapers, based on the identification and analysis of the ways mistakes are reported and the analysis of a selected case. It is assumed that there is a malfunction on the present errata publishing procedures and there is also a need to discover a way through which the reader is informed precisely about the facts. Within this context, errata is comprehended as an instrument to reveal the journalistic error and must be used every time the news need correction. Its function is to provide accountability towards the reader, because, acting with transparency in admitting mistakes, the news companies may keep their credibility.
Keywords: Errata. Online journalism. Ethics. Reader. Journalistic quality.

\section{A temática e sua problematização}

Errar é humano. Real e pragmática, a famosa frase pode ser aplicada não só nas relações entre pessoas, mas também em toda e qualquer atividade profissional. Não existe médico, engenheiro ou professor que não erre. Não existe jornalismo sem erro. 
Ênio Silveira, no prefácio do livro Grandes Pecados da Imprensa, de Sebastião Nery (2000), conta um excêntrico episódio com o jornalista Paulo Francis. "Com sua mordacidade habitual, ele me disse um dia que, em matéria de exatidão da imprensa, nem ao menos na data dos jornais se pode acreditar, sendo útil e oportuno confirmá-la sempre com o calendário mais próximo".

Em seu livro Ética no Jornalismo (2008), Christofoletti enfatiza a importância da correção dos erros. "Geralmente, as pessoas se apegam mais aos deslizes que aos acertos. A primeira impressão não é a que fica. A pior impressão é a que fica" (CHRISTOFOLETTI, 2008, p. 40). O autor aponta ainda possíveis causas para o erro jornalístico na obra Monitores de mídia: como o jornalismo catarinense percebe seus deslizes éticos (2003):

Estes erros decorrem da pressa de dar o furo, da pressão que a concorrência exerce sobre os profissionais, da falta de critérios na apuração dos casos. Mas qualquer que seja a justificativa usada, sempre haverá alguém para tachá-la de desculpa esfarrapada, jogando para baixo do tapete toda a profunda discussão que merece o tema da atuação da mídia na sociedade (CHRISTOFOLETTI, 2003, p. 25).

A questão da velocidade é certamente uma das causas para o erro jornalístico que tem recebido mais atenção por parte dos pesquisadores, principalmente na atualidade, em que a tecnologia já está incorporada às práticas jornalísticas e as tem modificado constantemente. A reflexão acerca da forma como as retificações são feitas no jornalismo online parte do princípio de que há uma deficiência no modelo atual e uma necessidade de descobrir uma maneira pela qual o leitor seja informado com precisão sobre os fatos.

A partir da identificação e análise das modalidades de comunicação do erro em veículos jornalísticos online selecionados, este artigo pretende levantar possibilidades para condutas mais adequadas e eficientes, contemplando princípios éticos do jornalismo, especialmente aqueles que convergem com o jornalismo online.

No cenário atual dos principais webjornais brasileiros, se o leitor recebe uma informação errada e não retorna à página da notícia para verificar se houve atualização (embora isso não garanta uma informação adicional, já que ele não saberá o que foi atualizado) ou se não consulta a lista de erratas (quando o veículo disponibiliza), não tem ciência sobre a correção. 
Embora a prerrogativa da divulgação de erratas esteja presente em alguns manuais de redação dos veículos jornalísticos brasileiros ${ }^{1}$, percebe-se, na prática, o quanto elas são escassas, têm pouca visibilidade e, muitas vezes, incorrem em mais erros, gerando um total descontrole no processo de retificação, como apontam Christofoletti e Prado (2005), referindo-se aos veículos impressos.

Quando comparado à publicação de erratas no jornalismo impresso, pode-se inferir que há algumas especificidades desse processo no jornalismo online, que vão além da simples mudança de meio. Uma delas é a possibilidade de retificação constante das notícias no jornalismo online, sem o atrelamento a uma periodicidade (a edição do dia seguinte, por exemplo), como nos veículos impressos. A oportunidade instantânea que os webjornais têm de reparo do erro é por vezes desperdiçada. Castilho e Vanzin (2008, p. 228) afirmam que "a incidência de erros na cobertura jornalística tende a crescer na medida em que aumenta a velocidade de publicação das notícias, como é o caso do jornalismo na web".

Outro fator que justifica a necessidade de rediscutir o modelo atual de publicação de erratas é o advento das mídias sociais². Dado o grande poder de compartilhamento da informação por meio dos sites de redes sociais e blogs, por exemplo, e levando em conta que não há um sistema claro de aviso ao leitor sobre as retificações, é temerário que uma notícia errada possa ser disseminada sem a devida correção. É a multiplicação do erro.

\footnotetext{
1 Manual de Redação e Estilo do jornal O Estado de S.Paulo: "Toda informação errada que o Estado publicar deverá ser retificada na edição seguinte, na mesma seção que a divulgou, sob o título Correção, ressalvados os casos excepcionais, que exijam maior destaque" (1990, p. 36).

Novo Manual de Redação da Folha de S.Paulo: "A Folha retifica, sem eufemismos, os erros que comete. A retificação deve ser publicada assim que a falha for contatada, mesmo que não haja pedido externo à Redação. As correções são feitas na seção 'Erramos' ou em caso de gravidade excepcional, na Primeira Página (aí também acompanhada do título 'Erramos')" (2001, p. 72).

Guia de Ética e Responsabilidade Social do Grupo RBS: "A RBS não oculta os erros cometidos e se dispõe a corrigi-los sistematicamente, tão logo tome conhecimento do equívoco. O texto da correção deve começar pela informação correta e explicar ao público, sem subterfúgios, qual foi o equívoco cometido" (2004, p. 19-20).

2 Segundo Raquel Recuero (2008), mídia social é aquela ferramenta de comunicação que permite a emergência das redes sociais. Para permitir que as redes sociais emerjam, esses meios de comunicação precisam subverter a lógica da mídia de massa (um->todos) para a lógica da participação (todos<->todos). Mídia social, assim, é social porque permite a apropriação para a sociabilidade, a partir da construção do espaço social e da interação com outros atores.
} 
No estudo "La ética en el ejercicio del periodismo: Credibilidad y autorregulación en la era del periodismo en Internet" (2008), os professores Josep Lluís Micó, João Canavilhas, Pere Masip e Carles Ruiz salientam a questão da responsabilidade na divulgação de uma informação no contexto das redes sociais.

Conceptos como la autenticidad o la independencia mantienen su relevancia, pero deben ser reconsiderados cuando el periodista pasa a formar parte de una red interactiva en la que ya no es la pieza central en el proceso de distribución de información. El profesional de la información debe diferenciarse de las otras fuentes por su equilibrio e imparcialidad $y$, sobre todo, por un sentido de la responsabilidad que le permita desarrollar su rol social, que se fundamenta en la confianza (CANAVILHAS et al., 2008, p. 31).

Seja no portal do veículo jornalístico ou em seus perfis nas redes sociais, é importante compreender a distinção entre atualização e retificação de uma notícia. No jornalismo online, uma informação pode ser atualizada com complemento de informações, sem significar, necessariamente, a retificação de um erro cometido. No entanto, nos dois casos, é desejável que o leitor saiba o que mudou naquela informação, seja por complementação ou retificação.

E ambas as práticas são deficitárias atualmente, após preliminar observação de alguns dos principais webjornais brasileiros: G1, portal de notícias da Rede Globo (www.g1.com.br); site do Jornal O Globo (www. oglobo.com.br); R7, portal de notícias do Grupo Record (www.r7.com); e site do jornal Folha de S. Paulo (www.folhaonline.com.br). A escolha dos veículos citados se deu pela necessidade de um recorte entre os diversos sites noticiosos existentes no país e, principalmente, devido à pluralidade de seus modelos de divulgação de erratas, para fins de comparação.

O site do Jornal $O$ Globo avisa seus leitores sobre data e hora da atualização das notícias, mas não especifica o que exatamente foi atualizado. Tampouco informa se essa atualização se deu por conta de uma informação equivocada ou se foi simplesmente uma complementação.

O $R 7$ também informa data e hora da atualização das notícias, mas igualmente não diz de que forma foi atualizada. No fim da página de cada notícia, há um ícone "Comunicar Erro", por meio do qual o leitor pode enviar um e-mail notificando um erro encontrado. Ainda assim, o veículo não avisa sobre a publicação de uma errata, seja ela percebida por ele mesmo ou pelo leitor. 
VIEIRA, L. S.

O site do Jornal Folha de S. Paulo possui a seção "Erramos", na qual há uma lista das notícias que foram retificadas, com a explicação do erro e sua correção. No entanto, o leitor só sabe que aquela notícia foi retificada se consultar a seção "Erramos", já que na página original da notícia não há nenhuma menção ao erro. $O$ jornal também avisa sobre a data e hora da atualização das notícias e possui um ícone "Comunicar Erro".

O G1 é o que possui um modelo mais próximo do desejável na divulgação de erratas. Embora não haja a opção específica de comunicação de um erro por parte do leitor, o veículo possui a seção "Correções" que, além de conter a lista de erratas, leva o leitor à página original da notícia, na qual, na maioria das vezes, há a explicação do erro (entre parênteses e com fonte em itálico). O difícil acesso à seção "Correções" - visível apenas no rodapé da homepage - e a falta de critérios claros para a divulgação da errata na página da notícia e na lista "Correções" fazem que o modelo do G1 seja também questionável em termos éticos. Das 15 erratas disponíveis na lista até a data da observação, duas não continham a menção ao erro na página original da notícia. Além disso, identificamos uma errata publicada em uma notícia do dia $14 / 4 / 2012^{3}$ que não foi incluída na seção "Correções". Vale mencionar ainda que não existe um histórico das erratas (a mais antiga era de 17 de novembro de 2011).

Como pôde ser visto nessa breve observação, há diferentes níveis de publicação de erros por parte dos webjornais selecionados. Além disso, chama atenção a falta de conexão entre a publicação da errata e a notícia original contendo o erro, o que acarreta prejuízos éticos e de qualidade jornalística que vão contra as recomendações do Código de Ética dos Jornalistas Brasileiros (1985). Em seu artigo 2º, está expresso que a "divulgação de informação, precisa e correta, é dever dos meios de comunicação". E o artigo 7ํairma que "o compromisso fundamental do jornalista é com a verdade dos fatos, e seu trabalho se pauta pela precisa apuração dos acontecimentos e sua correta divulgação".

Sinalizamos ainda a importância do aprofundamento não somente sobre o conteúdo textual relacionado às erratas, mas também sobre a questão da interface. A título de exemplo, podemos citar o espaço dado ao ícone "Comunicar Erro" na página do $R 7$ e da Folha Online, que possui a mesma hierarquização de importância de outros ícones como "enviar por email", "aumentar ou diminuir fonte" e "imprimir"; bem como o

3 Disponível em: <http://g1.globo.com/pop-arte/noticia/2012/04/volta-do-megadeth-tem-ver-com-nossa-crenca-crista-diz-guitarrista.html>. Acesso em: 14 mar. 2012. 
acesso quase imperceptível da seção "Correções" do G1, como mencionamos anteriormente.

Artur Araújo (2003) defende que os erros devem ser assumidos e publicados no mesmo espaço. O autor cita o comportamento da Reuters, agência internacional de notícias, que foi adotado desde 2002 e prega que "todos os erros publicados na Web devem ser informados e corrigidos dentro da própria matéria onde o erro incorreu" (ARAúJO, 2003, p. 85).

Numa análise preliminar, podemos inferir que o modelo da Reuters, semelhante ao do G1, é insuficiente por não contemplar os dois momentos de leitura da notícia: antes e depois da publicação da errata. O leitor que teve acesso à informação somente antes da retificação corre o risco de jamais ser informado sobre a errata e, ainda, de multiplicar o equívoco. Assim, nesse modelo, é beneficiado unicamente o leitor que teve acesso à notícia já retificada.

Como exemplo, citamos um recurso tecnológico já existente que poderia significar uma conduta mais adequada do veículo com seu leitor. Partindo do princípio de que é possível rastrear todo o percurso de navegação do leitor desde que ele esteja logado no site, o veículo poderia mensurar parte da audiência que teve acesso à página da notícia retificada e tomar algumas ações posteriores. Possíveis ações incluiriam desde o envio de um e-mail até um aviso nas redes sociais ou pelos feeds de $\mathrm{RSS}^{4}$ do referidos leitores.

Dessa forma, a análise da divulgação de erratas está inserida na discussão sobre parâmetros éticos para o jornalismo online e tem despertado crescente interesse na pesquisa científica. Um exemplo é o $e$-book Conjunto de Guías Éticas para hacer periodismo en la web, elaborado em agosto de 2010 por um grupo de jornalistas nos EUA, que contém recomendações éticas para os meios digitais, entre elas:

1. La publicación online tiene la oportunidad de servir a audiencias en formas nuevas y significativas.

2. Los valores periodísticos en áreas tales como la verdad, la comunidad y la democracia serán perdurables solo si aceptamos los drásticos cambios en las presiones y competencia que enfrentamos y en los productos que publicamos.

\footnotetext{
${ }^{4}$ A tecnologia do RSS (Really Simple Syndication) permite aos usuários da internet se inscrever em sites que fornecem feeds RSS. Estes são tipicamente sites que mudam ou atualizam o seu conteúdo regularmente. Para isso, são utilizados feeds RSS que recebem essas atualizações; dessa maneira, o utilizador pode permanecer informado de diversas atualizações em diversos sites sem precisar visitá-los um a um.
} 
3. Las guías éticas escritas basadas en aquellos valores son ingrediente esencial en la toma de decisiones requeridas en las variadas formas de medios emergentes.

4. La transparencia es una dimensión necesaria de la relación que los periodistas y las organizaciones periodísticas mantienen con sus audiencias. La transparencia debe estar enlazada con la responsabilidad institucional así como individual.

5. Los recursos limitados, la novedad de la publicación online o la carencia de protocolos no pueden llegar a ser una excusa para un trabajo de mala calidad o que cause daño (FRANCO, 2010, p. 10).

Especificamente em relação às erratas, o documento diz: "Corregiremos las equivocaciones tan pronta y claramente como sea posible. Estableceremos sistemas que hagan posible a los lectores alertarnos de los errores y responsabilizarnos". Os autores lançam ainda questões importantes sobre o tema, que ratificam o interesse desta pesquisa científica:

Cuando descubramos que hemos distribuido un error, consideraremos lo siguiente:

¿Cuál ha sido el probable impacto del error y cómo podremos resolverlo más efectivamente?

¿Qué tan apropiado es mantener un registro del error para los lectores que regresan a la historia o blogueros que han enlazado a ella en su forma original?

¿Qué convenciones de publicación podrían funcionar mejor (por ejemplo: texto tachado, correcciones anexadas, comentarios de corrección de los lectores, una nota del editor)? (FRANCO, 2010, p. 22).

Esses são alguns questionamentos que emergem junto à evolução do próprio jornalismo online. Embora não tenha a pretensão de responder às perguntas, este artigo pretende fomentar discussões éticas acerca das modalidades de divulgação do erro por parte dos webjornais.

\section{Reflexão teórica}

Tema caro à contemporaneidade, o tempo real é característica inerente ao jornalismo online, sob o ponto de vista da atualização contínua da informação. O sociólogo espanhol Manuel Castells (2004) destaca a transformação do tempo - que ele chama de "tempo intemporal" -, sob 
o paradigma da tecnologia da informação, como um dos fundamentos da sociedade atual. Para ele, as sociedades contemporâneas ainda estão em grande parte dominadas pelo conceito do tempo cronológico, mas esse tempo linear, irreversível, mensurável e previsível fragmenta-se na sociedade em rede.

Embora a instantaneidade acompanhe a prática jornalística desde sua gênese, a velocidade tem adquirido status de fetiche em nossos tempos, como aponta Sylvia Moretzsohn (2002). Segundo a autora, dentro da lógica do jornalismo no capitalismo, as empresas veem de maneira mais importante o fato de publicar primeiro a informação do que o de divulgar informações corretas.

Dessa forma, o fator "tempo", além de contribuir para a supervalorização da instantaneidade como prática corrente do ofício jornalístico, também prejudica, muitas vezes, a própria prática, levando o profissional e os veículos de informação a cometerem erros de imprecisão.

É possível citar como exemplo um fato noticiado em 29 de julho de 2011 por veículos online de todo o mundo, incluindo o site do jornal $O$ Globo, sobre o resultado de uma pesquisa que concluiu que "Usuários de Internet Explorer têm QI menor"5. Dias depois (3 de agosto de 2011), o portal de notícias $G 1$ e também outros sites esclareceram que "Pesquisa sobre inteligência de usuários do Internet Explorer era falsa: texto foi publicado em site feito com conteúdo roubado de outra página"6.

Uma sucinta análise desse episódio nos permite afirmar que, não bastasse a gravidade da repetição da notícia sem verificação, nota-se que, mais de oito meses após o fato, a página do jornal $O$ Globo com a informação errada continua no ar, sem qualquer menção à correção.

Partimos da afirmação de Rogério Christofoletti e Prado (2005) de que o jornalismo é uma atividade social que se apoia no compromisso de informar as pessoas dos principais acontecimentos da sociedade. Segundo eles, o público espera informação de qualidade, sem erros, sem distorções, sem incorreções. O coeficiente de confiabilidade das reportagens será proporcional ao nível de segurança do público em relação à mídia que consome.

Os autores também chamam atenção para o fato de que os erros cometidos pelos veículos jornalísticos estão diretamente ligados à

5 Disponível em: <http://oglobo.globo.com/tecnologia/usuarios-de-internet-explorer-tem-qi-menor-diz-estudo-2871349\#ixzz1p2mQuNKI>. Acesso em: 14 mar. 2013.

6 Disponível em: <http://g1.globo.com/tecnologia/noticia/2011/08/pesquisa-sobre-inteligencia-de-usuarios-do-internet-explorer-era-falsa.html>. Acesso em: 14 mar. 2013. 
qualidade e à ética. Sustentam que todos os meios são passíveis de erros, mas a condição de velocidade inerente ao jornalismo online torna a discussão necessária, já que falhas que podem comprometer a qualidade do jornalismo, enquanto serviço social, geram transtornos de ordem ética. Segundo os autores, a desculpa da agilidade não pode prejudicar a correção ou a precisão das informações veiculadas.

Francisco Karam (2004), citando o professor Daniel Cornu, enfatiza a necessidade de o jornalista constantemente recorrer aos princípios deontológicos constituídos na história da profissão, entre eles a exatidão, descrição correta dos fatos, informações com origem conhecida, retificação de erros, confirmação de dados, inclusão das informações essenciais, fidelidade a textos ou documentos.

Cabe ressaltar aqui a carência de estudos brasileiros acerca das erratas no jornalismo online, sob o ponto de vista ético. Levando em consideração que se trata de um tema caro à qualidade do fazer jornalístico no meio digital, este artigo inicia reflexões que serão aprofundadas na dissertação de mestrado da autora.

\section{G1: Breve análise de uma errata}

No dia 16 de julho de 2012, o portal G1 publicou a notícia "Homem furta cervejas de caminhão e é preso em flagrante em Joinville"7, cuja fonte principal foi um vídeo enviado pela Polícia Militar da cidade, que registrou o momento do furto.

Seis horas após a publicação da notícia, o veículo divulgou a seguinte errata: "Ao ser publicada, esta reportagem informou que o caso ocorreu na manhã de domingo, 15. Na verdade, o vídeo foi divulgado no domingo pela polícia, mas o fato ocorreu cerca de um ano atrás. A polícia não informou porque divulgou o vídeo como se fosse recente. $O$ erro foi corrigido nesta reportagem às $16 \mathrm{~h} 02$ ". O G1 publicou a errata na página da notícia e também na seção "Correções".

Há alguns vieses interessantes nessa notícia que merecem uma análise um pouco mais aprofundada. Embora tenha publicado a errata de uma maneira correta do ponto de vista ético (tanto na página da notícia quanto na seção de erratas), assinalamos algumas lacunas que deveriam ter sido preenchidas pelo veículo com um olhar mais abrangente para o leitor.

7 Disponível em: <http://g1.globo.com/sc/santa-catarina/noticia/2012/07/homem-furta-cervejas-de-caminhao-e-e-preso-em-flagrante-em-joinville.html>. Acesso em: 14 mar. 2013. 


\section{Duvidar e verificar é a melhor forma para evitar erros}

Uma das reflexões suscitadas pela análise da notícia abrange o próprio fazer jornalístico. Um dos princípios éticos do jornalismo é a verificação da informação, independente da plataforma de publicação. Perguntar à Polícia Militar a data do vídeo e entrevistar profissionais, para não apenas reproduzir em texto as imagens divulgadas, estão entre as ações que poderiam ter evitado esse grave erro.

Artur Araújo (2003) identifica a forma de lidar com as erratas como um problema ético dentro da prática do jornalismo online. Di Franco (1995) vai além e aponta alguns sintomas que se apresentam nas redações jornalísticas, todos de ordem prejudicial, segundo o autor, à qualidade informacional. Dentre esses sintomas, estão a apuração mal feita, a carência de informação especializada e o não reconhecimento dos erros cometidos.

Criticamos uma troca de legendas, um empastelamento qualquer, um erro de diagramação. Mas não nos envergonhamos da informação incorreta, da matéria mal apurada, da manipulação informativa, do sensacionalismo brega, da notícia incompetente. Esquecemos que a qualidade é o outro nome da ética (DI FRANCO, 1995, p. 166).

\section{Webjornal deve pensar no leitor que teve acesso à notícia antes da errata}

Durante seis horas, a notícia foi divulgada e esteve em destaque no portal $G 1$ sem qualquer menção ao erro. Quantas pessoas tiveram acesso a essa informação e pensaram que o vídeo era do dia anterior (e não de um ano atrás)? E desses leitores, quantos retornaram à página da notícia após a divulgação da errata?

Para o G1, é possível rastrear tecnicamente o percurso do leitor por seu portal e saber quantas e quais notícias ele leu, quanto tempo demorou em cada página, entre outras informações. Levando em consideração o compromisso do veículo jornalístico com seu leitor e a possibilidade de relacionamento que a internet permite, um simples aviso poderia reconectar o leitor com a notícia correta.

Destaca-se aqui a importância da abordagem dos conceitos éticos sob o viés relacional, com o olhar voltado para o leitor, e não somente para o respeito a regras estabelecidas, embora elas sejam de fundamental 
importância no exercício do jornalismo. Assim, entenderemos a ética conceituada em fontes filosóficas, como sugere Marilena Chauí (1998):

Desde sua origem, portanto, o assunto comporta duas faces: uma no indivíduo, em seu "temperamento", e outra na sociedade. A ação só é ética se realizar a natureza racional, livre e responsável do agente e se o agente respeitar a racionalidade, liberdade e responsabilidade dos outros agentes, de sorte que a subjetividade ética é uma intersubjetividade (CHAUÍ, 1998).

Considerando a publicação das erratas como parte importante do relacionamento entre os veículos jornalísticos online e o leitor, é relevante levantar possibilidades que se aproximem da qualidade que se espera dos produtos e processos jornalísticos.

\section{Convergência também na divulgação das erratas}

No simpósio online da Fundación Nuevo Periodismo Iberoamericano (FNPI) "Cómo rectificar un error en medios digitales y redes sociales" (26 de abril de 2012), a jornalista peruana Esther Vargas destacou que a convergência de mídias $^{8}$ precisa ser aplicada no jornalismo também para a divulgação das erratas. "Devem ser usados todos os espaços disponíveis, que incluem não só o website do veículo, mas também as redes sociais, impressos, entre outros".

Na notícia analisada, o $G 1$ poderia ter utilizado seu perfil no Twitter (https://twitter.com/g1sc) para divulgar a errata, que não se trata apenas de uma imprecisão ortográfica ou troca de um nome, por exemplo. $O$ fato de o vídeo ter sido feito há um ano é um dado muito importante, que põe em xeque até mesmo a relevância da notícia. No Twitter, o G1 publicou apenas um tweet com o texto da manchete da notícia. Sem retificação alguma.

Além disso, o G1 possui um aplicativo "Seus amigos no G1", que tem integração com o portal e mapeia os leitores que acessaram a página da

\footnotetext{
8 Segundo Suzana Barbosa (2009, p. 37), a convergência jornalística é um processo multidimensional que, facilitado pela implantação generalizada das tecnologias digitais de telecomunicação, afeta os âmbitos tecnológico, empresarial, profissional e editorial dos meios de comunicação. Esse processo propicia uma integração de ferramentas, espaços, métodos de trabalho e linguagens anteriormente desagregados, de forma que os jornalistas elaboram conteúdos que sejam distribuídos através de múltiplas plataformas, por meio das linguagens próprias de cada uma delas.
} 
notícia. Ações como o envio de um e-mail ou uma mensagem pelo próprio Facebook desses leitores poderiam minimizar a disseminação do erro.

Segundo informação que consta na página da notícia, até o dia 18 de julho de 2012, a matéria havia sido compartilhada por dez pessoas no Facebook e por uma pessoa no Twitter. Se imaginarmos, de forma hipotética, que cada pessoa tem 100 amigos, a notícia foi vista por 1.100 pessoas. Tanto no Twitter, quanto no Facebook, é exibido o título e a chamada da notícia, que não mencionam o erro. Caso essas 1.100 pessoas não cliquem no link compartilhado, elas não terão acesso à informação correta.

Diante dessa breve análise, podemos concluir que a forma como as erratas são divulgadas atualmente é falha, sobretudo quando se trata da qualidade do relacionamento com o leitor. A dissertação de mestrado da autora constituirá um aprofundamento do tema e pretende identificar e analisar as modalidades de correção do erro visando uma proposta de publicação de erratas.

\section{Referências}

ARAÚJO, A. V. A ética na velocidade do tempo real. Revista de Estudos de Jornalismo, v. 6, n. 1, p. 79-86, 2003.

BARBOSA, S. Convergência jornalística em curso: as iniciativas para integração de redações no Brasil. In: RODRIGUES, C. (Org.). Jornalismo on-line: modos de fazer. Rio de Janeiro: PUC-Rio, 2009.

BRASIL. Código de ética dos jornalistas brasileiros. 1987. Disponível em: <http:// www.fenaj.org.br/federacao/cometica/codigo_de_etica_dos_jornalistas_brasileiros.pdf>. Acesso em: 30 jan. 2013.

BUCCl, E. Sobre ética e imprensa. São Paulo: Companhia das Letras, 2000.

CANAVILHAS, J. et al. La ética en el ejercicio del periodismo: credibilidad y autorregulación en la era del periodismo en Internet. Revista Estudos em Comunicação, n. 4, 2008.

CASTELLS, M. A galáxia da Internet: reflexões sobre a Internet, os negócios e a sociedade. Lisboa: Editora Fundação Calouste Gulbenkian, 2004.

CASTILHO, C.; VANZIN, T. Erro informativo e produção colaborativa na web. Revista Estudos em Jornalismo e Mídia, v. 5, n. 2, jul./dez. 2008.

CHAUÍ, M. Ética e violência. Teoria \& Debate, n. 39, 1998.

CHRISTOFOLETTI, R. Monitores de mídia: como o jornalismo catarinense percebe os seus deslizes éticos. Florianópolis: Ed. UFSC, 2003. 
VIEIRA, L. S.

CHRISTOFOLETTI, R.; PRADO, R. O. do. Erros nos jornais: aspecto ético e fator de comprometimento de qualidade técnica. In: XXVIII CONGRESSO BRASILEIRO DE CIÊNCIAS DA COMUNICAÇÃO, 2005, Rio de Janeiro. Anais eletrônicos... Rio de Janeiro, 2005. Disponível em: <http://monitorando.files.wordpress.com/2007/11/ erros_nos_jornais.pdf>. Acesso em: 30 jan. 2013.

CHRISTOFOLETTI, R. Ética no jornalismo. São Paulo: Contexto, 2008.

DI FRANCO, C. A. Jornalismo, ética e qualidade. Petrópolis: Vozes, 1995.

FOLHA DE S. PAULO. Manual de redação. São Paulo: Folha de S. Paulo, 2001.

FRANCO, G. (Org.). Conjunto de guías éticas para hacer periodismo em la web. Poynter Institute, 2010. Disponível em: <http://knightcenter.utexas.edu/pt-br/ ebook/conjunto-de-diretrizes-eticas-para-fazer-jornalismo-na-web-pt-br>. Acesso em: 30 jan. 2013.

GRUPO RBS. Guia de ética, qualidade e responsabilidade social / Grupo RBS. 2. ed. rev. e ampl. Porto Alegre: RBS Publicações, 2007. Disponível em: <http://www. gruporbs.com.br/responsabilidade_social/guia_etica/etica_rbs.pdf>. Acesso em: 30 jan. 2013.

KARAM, F. J. C. A ética jornalística e o interesse público. São Paulo: Summus, 2004. MARTINS FILHO, E. L. Manual de redação e estilo de O Estado de S. Paulo. 3 ed. rev. e ampl. São Paulo: O Estado de S. Paulo, 1997.

MORETZSOHN, S. Jornalismo em "tempo real": O fetiche da velocidade. Rio de Janeiro: Revan, 2002.

NERY, S. Grandes pecados da imprensa. São Paulo: Geração Editorial, 2000.

RECUERO, R. O que é mídia social? Disponível em: <http://www.pontomidia.com. br/raquel/arquivos/o_que_e_midia_social.html>. Acesso em: 30 jan. 2013.

Recebido: 28/01/2013

Received: 01/28/2013

Aprovado: 20/02/2013

Approved: 02/20/2013 